\title{
Escolhas discursivas em textos sobre a expansão de terras indígenas no perímetro urbano de Dourados
}

\author{
Opciones discursivas en textos sobre la expansión de tierras \\ indígenas en el perímetro urbano de Dourados
}

\section{Discursive choices in texts on the expansion of indigenous lands in the urban perimeter of Dourados}

\author{
Eliane Aparecida Miqueletti ${ }^{1}$, Amanda Freire da Silva²
}

\begin{abstract}
RESUMO: Neste trabalho, fruto de uma pesquisa de Iniciação Científica, apresentaremos o corpus coletado e algumas reflexões sobre o objetivo principal da investigação, isto é, analisar como escolhas discursivas, em textos publicados por jornais de Dourados na versão on-line, marcam a representação sobre o indígena na relação com o não indígena, com destaque para a escolha de temas e figuras. Para isso, recorremos ao aporte teórico da semiótica francesa. O corpus foi constituído por textos publicados entre janeiro de 2016 e abril de 2017, em quatro principais portais de notícias de Dourados: Dourados Agora, Dourados News, O Progresso e Diário MS. Neste artigo, apresentamos as análises de textos que abordam a posse por terras no perímetro urbano de Dourados. Verificamos que a seleção de temas e de figuras, dos textos imagéticos e o emprego das palavras "invasão" e/ou "ocupação" revelam posicionamentos dos enunciadores em relação aos fatos narrados. O clima de tensão/conflito é enfatizado.
\end{abstract}

PALAVRAS-ChaVe: Mídia. Semiótica francesa. Conflitos por terra. Escolhas discursivas.

RESUMEN: En este artículo, resultado de una investigación de Iniciación Científica, presentaremos el corpus recopilado y algunas reflexiones sobre el objetivo principal de la investigación, es decir, analizar cómo las elecciones discursivas, en textos publicados por los periódicos de Dourados en la versión en línea, marcan la representación sobre lo indígena en relación con lo no indígena, con énfasis en la elección de temas y figuras. Para ello, recurrimos a la contribución teórica de la semiótica francesa. El corpus consistió

\footnotetext{
${ }^{1}$ Doutora em Estudos da Linguagem. Professora da Faculdade de Comunicação Artes e Letras da Universidade Federal da Grande Dourados (FACALE/UFGD). E-mail: elianemiq@gmail.com.

${ }^{2}$ Graduanda em Direito pela Universidade Estadual de Mato Grosso do Sul e em Letras pelo Centro Universitário da Grande Dourados-Unigran. E-mail: amandafreiresilva9@gmail.com.
} 
en textos publicados entre enero de 2016 y abril de 2017, en cuatro portales de noticias principales de Dourados: Dourados Agora, Dourados News, O Progress y Diário MS. En este artículo, presentamos el análisis de textos que abordan la tenencia de la tierra en el perímetro urbano de Dourados. Verificamos que la selección de temas y figuras, los textos de imágenes y el uso de las palabras "invasión" y / u "ocupación" revelan las posiciones de los enunciadores en relación con los hechos narrados. Se enfatiza el clima de tensión / conflicto.

PALABRAS CLAVE: Medios de comunicación. Semiótica francesa. Conflictos por la tierra. Elecciones discursivas.

ABSTRACT: In this work, the result of a research of Scientific Initiation, we are going to present the collected corpus and some reflections on the main objective of the investigation, that is to say, to analyze how discursive choices, in texts published by newspapers of Dourados in the online version, mark the representation of the indigenous in relation to the non-indigenous, with emphasis on the choice of themes and figures. For this, we resort to the theoretical contribution of French semiotics. The corpus consisted of texts published between January 2016 and April 2017 in four main Dourados news portals: Dourados Agora, Dourados News, O Progresso and Diário MS. In this article, we present the analyses of texts that deal with land tenure in the urban perimeter of Dourados. We find that the selection of themes and figures, imagery texts and the use of the words "invasion" and / or "occupation" reveal the position of the enunciators in relation to the facts narrated. The tension / conflict climate is emphasized.

KEYWORDS: Media. French semiotics. Land conflicts. Discourse choices.

\section{Introdução}

A mídia destaca-se, cada vez mais, como uma das principais fontes de influência social, valendo-se da articulação entre diferentes linguagens, molda os valores disponibilizados aos sujeitos socialmente envolvidos. Ela "vende" uma ideia ao persuadir o leitor ${ }^{3}$. $\mathrm{E}$ isso não poderia ser diferente no contexto dos veículos midiáticos de Dourados, com destaque, neste trabalho, para a representação do indígena na sua convivência com o não indígena.

Essa relação é enfatizada nas mídias locais desde a formação do município, integrando, principalmente, discussões em torno das questões territoriais, como

${ }^{3}$ Entre os estudiosos do discurso que apontam para isso, destacamos Charaudeau (2006) e Discini (2005). 
estudiosos de diferentes áreas já mostraram. No campo dos estudos semióticos, destacamos os trabalhos de Limberti (2012), pesquisadora que trata da presença indígena em notícias do jornal $O$ Progresso, entre os anos de 1951 e 2000, e Miqueletti $(2007,2015)$, que aponta em suas pesquisas, entre outras questões, para a construção da identidade indígena na mídia douradense.

Neste artigo, apresentamos o recorte de algumas reflexões realizadas em uma pesquisa de Iniciação Científica (PIBIC), desenvolvida entre agosto de 2016 e julho de 2017. Partimos do princípio de que a mídia, com destaque para o jornalismo, é bastante presente no cotidiano das pessoas. Em certa medida, é reflexo das posições ideológicas do público leitor e meio influenciador, como afirma Rossi (2005, p. 7):

"Jornalismo, [...] é uma fascinante batalha pela conquista das mentes e corações de seus alvos: leitores, telespectadores ou ouvintes. Uma batalha geralmente sutil e que usa uma arma de aparência extremamente inofensiva: a palavra $[\ldots]^{\prime \prime}$.

Nesse sentido, o objetivo principal da pesquisa foi analisar como escolhas discursivas, em textos publicados nos principais portais de notícias douradenses, marcam a representação sobre o indígena na relação com o não indígena, na região de Dourados, com destaque para a articulação entre temas e figuras. Para isso, utilizamos como aporte teórico a semiótica francesa, teoria que tem como foco de investigação a construção da significação nos textos.

Para a composição do corpus, coletamos textos, publicados entre janeiro de 2016 e abril de 2017, nos seguintes portais de notícias de Dourados: Dourados Agora, Dourados News, O Progresso e Diário MS. Usamos o recurso de busca dos portais indicados, inserindo as palavras "aldeia (s)", "índio (s)" e "indígena (s)". Além desse critério, os textos selecionados deveriam ser classificados como sincréticos, ou seja, que gerenciam mais de uma linguagem (o verbal, parte escrita, e o não verbal, imagens) na construção do sentido.

Organizamos os textos coletados nas seguintes temáticas: ação social (textos que tratam de atividades em prol da comunidade indígena, muitas 
realizadas por entidades privadas, ou pela prefeitura, como ações de saúde bucal e vacinação), comemorações (textos que abordam festividades dentro da comunidade indígena, boa parte relacionada à Semana dos Povos Indígenas), conflitos/terra (textos sobre a discussão da posse de terras entre indígenas e não indígenas), educação (textos relacionados à formação educacional na aldeia, ou à formação universitária) e outros (textos que não se encaixam nas temáticas anteriores, abordam questões diversas, entre elas entrevistas sobre as condições da Reserva Indígena de Dourados). Tabulamos a quantidade encontrada, sendo 156 textos em 2016 e 70 em 2017, resultando nas seguintes porcentagens, de acordo com a quantidade dividida entre temáticas:

Gráfico 1 - Textos recolhidos em $2016 \quad \begin{aligned} & \text { Gráfico } 2 \text { - Textos recolhidos em } \\ & 2017\end{aligned}$
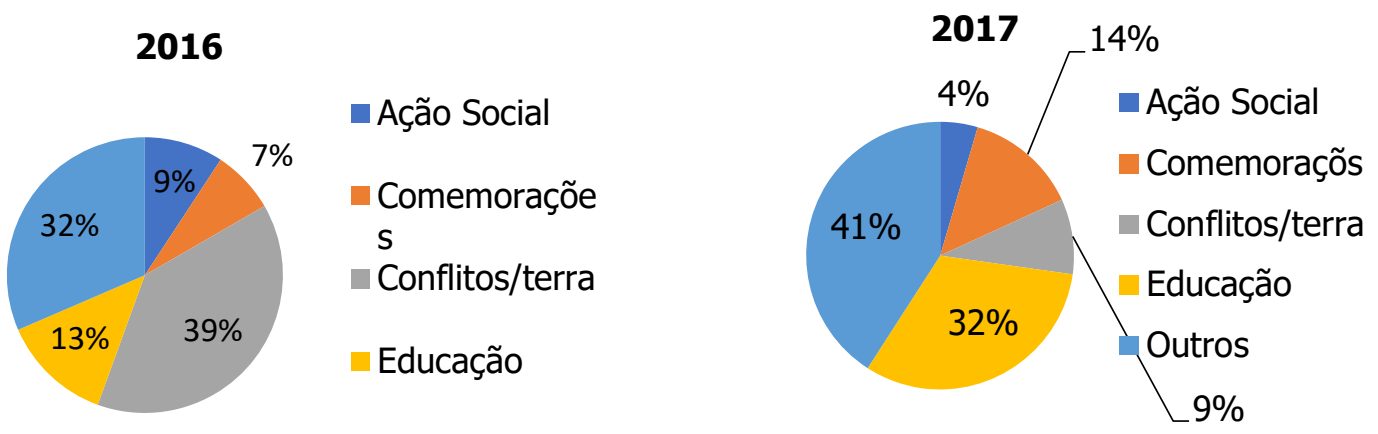

Fonte: Elaborado pelas autoras.

Gráfico 3 - Conjunto de textos recolhidos entre 2016 e 2017 2016 - 2017

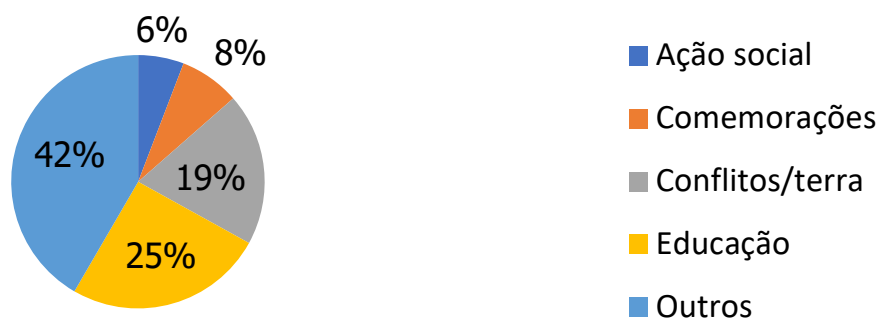

Fonte: Elaborado pelas autoras. 
Conforme disposto nos gráficos, verificamos que no ano de 2016, do qual coletamos maior número de textos, o tema "conflitos/terra" é o que mais sobressaiu. Na leitura do corpus, notamos que esses textos estavam ligados principalmente à expansão das terras indígenas em municípios da região sul do Estado. Escolhemos esses para o foco das análises. A escolha foi decidida por percebermos que os textos desse grupo destacam-se pela ênfase na relação entre indígenas e não indígenas. Dentro do conjunto desses textos, fizemos, ainda, outro recorte: selecionamos apenas os textos que envolviam a posse pela terra em torno do perímetro urbano de Dourados, caso que gerou discussões, sobretudo no primeiro semestre de 2016.

Após esse preâmbulo, na sequência apresentaremos parte do arcabouço teórico que serviu de base para nossa pesquisa - considerações sobre o surgimento da teoria semiótica francesa e o percurso gerativo de sentido; a concepção de texto para semiótica; os conceitos de texto sincrético, tematização e figurativização. Logo depois, realizaremos apontamentos analíticos em torno da seleção discursiva para a construção da representação sobre os indígenas, na relação com o não indígena, em textos sobre a posse de terras na região do perímetro urbano de Dourados. As considerações finais sintetizarão as observações realizadas durante a pesquisa.

\section{Considerações Teóricas}

\section{A semiótica francesa e o percurso gerativo de sentido}

A semiótica de linha francesa, também conhecida como Escola de Paris, semiótica narrativa e discursiva, caracteriza-se por uma história de amadurecimento teórico. O livro Semântica estrutural(1966), de Algirdas Julien Greimas, é reconhecido como o seu marco inicial. Fiorin (1995) destaca essa obra como o "discurso fundador" de uma teoria que é constituída ao longo do tempo, a partir de influências de diferentes áreas. Na fundamentação inicial, identificam- 
se bases teóricas advindas de teóricos como Propp, expoente da narratalogia, Merleau Ponty, da fenomenologia, Hjelmslev e Saussure, estudiosos da Linguística.

A partir das influências citadas e de outras que foram e ainda são incorporadas aos conceitos analíticos da semiótica discursiva, constitui-se uma ciência que busca estudar os mecanismos discursivos de significação, "o que o texto diz e como ele faz para dizer o que diz" (BARROS, 2005, p. 13). Nesses termos, a semiótica entende que a verdade nada mais é do que uma construção, pelo discurso, de uma "ilusão da verdade". Como teoria da significação, seu trabalho é o de "explicitar, sob a forma de uma construção conceptual, as condições de apreensão e de produção do sentido" (GREIMAS; COURTÉS, 1979, p. 345).

A semiótica se propõe a verificar as estratégias utilizadas em um texto para dizer o que diz. O texto é um todo organizado, como explica Fiorin (1995, p. 165-166), "Texto" origina-se do verbo latino "texo, is, texui, textum, texere, que quer dizer tecer", e como um tecido "não é um amontoado desorganizado de fios, o texto não é um amontoado de frases". Ou seja, envolve elaboração, é tudo o que emana sentido a partir da junção entre plano de conteúdo (o significado) e plano de expressão (forma de apresentação do conteúdo). Pode ser lido a partir de determinada organização estrutural. Uma sala, por exemplo, pode ser lida a partir da sua arquitetura, das cores de suas paredes, da distribuição dos móveis.

É necessário ponderar, ainda, que o homem é um ser que expressa suas ideias e sentimentos a partir de diferentes linguagens. Assim, a semiótica francesa preocupa-se com os sentidos manifestados pelas diversas construções textuais, sejam elas verbais, não verbais ou sincréticas. As sincréticas agregam textos construídos a partir da mobilização de mais de uma linguagem. Como aponta Discini (2005, p. 57): "No plano de conteúdo estão as vozes em diálogo, está o discurso. No plano da expressão está a manifestação do sentido imanente, feita por meio da linguagem sincrética, que integra o visual e o verbal sob uma 
única enunciação". No caso dos textos jornalísticos coletados para a análise da pesquisa, optamos por selecionar aqueles que também apresentassem uma imagem, marcando assim o sincretismo na relação com a parte verbal do texto.

Ainda tendo em vista o conceito de texto para a semiótica francesa, na análise, devemos considerar a sua estruturação e os aspectos intencionais comunicativos. Sobre isso afirma Barros (2005, p. 7): "Um texto define-se de duas formas que se complementam: pela organização ou estruturação que faz dele um 'todo de sentido', como objeto da comunicação que se estabelece entre um destinador e um destinatário". Corroborando com Barros, Fiorin (1995) explica que há duas maneiras de entender e de analisar um texto: como objeto de significação (mecanismos intradiscursivos), envolvendo a estruturação discursiva, e como objeto histórico (mecanismos interdiscursivos), implicando o caráter social, a análise com base na formação ideológica na qual o texto foi produzido.

Para analisar a construção dos sentidos nos textos, Greimas apresenta uma metodologia conhecida como "Percurso Gerativo de Sentido". A proposta é verificar níveis de sentido, do mais simples e abstrato, para o mais complexo e concreto. Em síntese, como apresentam Barros (2005) e Fiorin (2005) - dois importantes precursores da teoria no Brasil -, o percurso é analisado em três níveis: o fundamental, o narrativo e o discursivo. 0 nível fundamental é a etapa base do texto, na qual é verificada a sustentação do percurso gerador de sentido, sintetizado a partir da seleção de valores em oposição.

O nível narrativo é entendido a partir do conceito de narratividade, todo texto é organizado a partir da relação entre sujeitos e a busca de objetos-valores, processo que implica quatro etapas: a manipulação, a competência, a performance e a sanção. Na etapa da manipulação, um sujeito (o destinadormanipulador) procura manipular o outro para a realização de uma ação, pretende levá-lo a querer e/ou dever fazer alguma coisa. Para realizar a ação o sujeito precisa de valores modais (querer, dever, saber e poder-fazer), esta é a etapa da competência, o sujeito é dotado de um saber e/ou poder fazer para realizar a 
transformação. Assim, consecutivamente, a próxima etapa é a da performance, na qual ocorrem as mudanças nas relações do sujeito com os valores e fazeres, a ação propriamente dita. A última etapa da narrativa é a sanção, o percurso do destinador-julgador, ele verificará a realização da performance. Nessa última fase estabelecem-se as operações cognitivas (reconhecimento) e/ou pragmáticas (retribuição), de acordo com o cumprimento ou não da ação, o sujeito pode ser recompensado ou castigado.

Por fim, no nível discursivo temos a concretização da história, instância da enunciação, na qual se encontram as marcas de ideologias, as intensões, os valores selecionados para a construção de determinada significação no texto. Analisamos as projeções de pessoa, tempo e espaço discursivo; a instauração da enunciação. Na projeção da enunciação no enunciado, destacam-se o efeito de proximidade (eu-aqui-agora) e o de distanciamento (ele-lá-então), conhecidos, respectivamente, como debreagem enunciativa e debreagem enunciva. Cabe destacar, também, o uso da debreagem interna, que ocorre quando o locutor faz uso do discurso direto trazendo o "sujeito" para dentro da fala, criando o efeito de realidade para a aprovação do que é dito. Semanticamente, o nível discursivo é composto pela escolha de temas e figuras. Em suma, os temas são categorias abstratas (conceitos) que organizam os elementos do mundo natural, e as figuras são termos concretos que têm um correspondente na realidade construída pelo discurso.

Tendo em vista que o objetivo principal da nossa pesquisa envolveu a construção dos sentidos a partir da análise das escolhas discursivas que marcam a representação sobre o indígena, discorreremos, no tópico seguinte, um pouco mais sobre a tematização, a figurativização e alguns aspectos teóricos utilizados para a análise dos textos imagéticos, fotografias das cenas, dos sujeitos envolvidos nas situações retradas.

\section{Tematização, figurativização e os textos imagéticos}


Na semântica do nível discursivo do percurso gerativo de sentido, as escolhas de temas e de figuras revelam-se como um dos procedimentos de construção da significação do discurso. Segundo Fiorin (2005, p. 91):

Temas são categorias que organizam, categorizam, ordenam os elementos do mundo natural: elegância, vergonha, racionar, calculista, orgulhos, etc. [...] A figura é o termo que remete a algo existente no mundo natural: árvore, vagalume, sol, correr, brincar, vermelho, quente, etc.

A importância do entendimento desses conceitos está na verificação de suas escolhas e na lógica de sua organização ao longo do processo textual. Eles revelam os objetivos do texto, as intenções ideológicas do enunciador. Nesse sentido, dizemos que todo texto é temático, pois envolve um ou mais conceitos abordados no nível narrativo, e pode ser menos ou mais figurativo, dependendo da intensidade da cobertura de figuras. Essas dão concretude ao texto, portam valores aos olhos do leitor que passa a identificar-se ou não com as escolhas realizadas. Como sintetiza Barros (2005, p. 98), a escolha dos temas e das figuras assegura "a coerência semântica do discurso e cria, com a concretização figurativa do conteúdo, efeitos de sentido sobretudo de realidade".

Para classificar a manutenção da recorrência de traços semânticos ao longo da construção textual, sejam eles temáticos ou figurativos, a semiótica recorre ao termo "isotopia". A ligação e distribuição de traços semânticos caracteriza a coerência do texto; no entanto, é preciso entender que, em alguns casos, a invocação de termos que remetem à isotopia oposta não significa que o texto esteja incoerente, mas pode indicar uma crítica do enunciador sobre determinado assunto, como ocorre no uso de "assassinato" em um texto que trata de procedimentos operatórios.

Voltando nossa atenção para os textos analisados neste trabalho - textos jornalísticos que envolveram a posse pela terra em torno do perímetro urbano de Dourados -, verificamos que constituem um todo de sentido a partir da articulação entre verbal e não verbal. É a partir do ponto de vista do enunciador, 
ou melhor, das suas investiduras para "atingir" o enunciatário, que, por exemplo, a parte não verbal, composta pelas fotografias, é selecionada.

Debruçando sobre a relação entre verbal e não verbal, Barthes (1984) destaca dois modos: a ancoragem - quando a parte verbal auxilia na construção do sentido explicando o que consta na imagem, como ocorre nas legendas - e a etapa - quando a imagem e a escrita se complementam, a exemplo das histórias em quadrinhos.

Nesse sentido, Barthes (1984, p. 32) afirma que "[...] toda imagem é polissêmica, implicando, subjacente aos seus significantes, uma 'cadeia flutuante' de significados, dos quais o leitor pode escolher alguns e ignorar os outros", assim o texto verbal influencia na redução da ambiguidade da imagem.

No que se refere mais especificamente à análise da construção da imagem, além da parte figurativa que a compõe, ou seja, elementos que representam as figuras do mundo, "o real" que conhecemos, é preciso observar a parte plástica, ligada aos sentidos construídos no plano de expressão. Esta, de acordo com trabalhos de Greimas, Floch e Thürlemann, pode ser analisada de acordo com três categorias, como aborda Hernandes (2005): a cromática está relacionada às cores presentes na imagem, combinações, contrastes, tonalidades, gradações; a eidética refere-se à construção das formas, as combinações entre linhas e volumes (verticais versus diagonais, curvilíneo versus retilíneo, uniforme versus multiforme) e a topológica, ligada à análise do posicionamento dos elementos distribuídos no espaço, conforme o contraste (alto versus baixo, central versus periférico).

A importância da identificação da relação entre verbal e não verbal e das categorias que compõem a imagem, indicadas neste tópico, recai nas escolhas que os enunciadores realizam tendo em vista intencionalidades, a construção de uma representação sobre o fato narrado e os sujeitos envolvidos. É em vista disso que encaminhamos o tópico seguinte, no qual faremos algumas intervenções na análise das imagens. 


\section{A análise de escolhas discursivas na construção de textos sobre a expansão de terras indígenas em Dourados}

Os textos selecionados para as análises, como já apontado anteriormente, abordam o questionamento sobre a ampliação de terras indígenas próximas ao perímetro urbano de Dourados. Ao todo, obtivemos 19 textos, sendo: 02 do $O$ Progresso, 01 do Dourados News e 16 do Diário MS, publicados entre fevereiro de 2016 e janeiro de 2017, não sendo encontradas publicações sobre esse assunto no Dourados Agora.

Os leitores de textos on-line buscam uma leitura mais rápida das informações, o que é facilitado pelos recursos tecnológicos. Com a ajuda do mouse é possível percorrer visualmente os textos com as últimas notícias, mudar de página, abrir vários links. Dessa forma, esses leitores atêm-se, com mais frequência, à leitura dos seguintes elementos: título/manchete, chapéu, fio ${ }^{4}$, imagem e legenda.

Ao abrir a página, o que chama a atenção do leitor, fisgando-o para a leitura, são basicamente esses elementos, e, claro, posteriormente o interesse pelo assunto, que o levará a ler o restante do conteúdo disponível. Dessa forma, recortamos essas partes para o foco de nossa investigação. Sobre o título, Guimarães (1995, p. 51) afirma que "não são meros artifícios publicitários, mas chaves para a decodificação da mensagem, se convenientemente propostos" e é com esse olhar que analisamos os recursos textuais recortados, como partes que antecipam sentidos, conduzem a interpretação.

Olhamos para os textos compreendendo que os casos relatados são frutos das práticas sociais próprias do contexto no qual estão inseridos e que os sentidos construídos por meio do discurso resultam da articulação interna e em função de

${ }^{4}$ Chapéu e fio são termos do jornalismo utilizados para denominar as seguintes partes, respectivamente: um termo que aparece a esquerda do texto, em destaque, normalmente negrito e funciona como palavra-chave, guia, antecedendo, nos textos analisados, o fio. $O$ fio constitui-se de uma ou duas linhas, acima ou abaixo do título do texto, em fonte menor, que traz informações gerais sobre o fato. 
quem, como e de que lugar fala. Na leitura dos textos jornalísticos ${ }^{5}$, notamos que, além de informar, há tendência a direcionar o posicionamento sobre o caso da expansão territorial indígena e, consequentemente, sobre os indígenas na relação com os não indígenas de Dourados. Os indígenas são "invasores", causadores de desordem e terror no perímetro urbano. Entre situações de resistência e submissão do indígena na relação com o não indígena, implicitamente está, em termos semióticos, a relação eufórica (posse) e disfórica (perda) envolvidas na busca pelo objeto-valor "terra", apresentado pelo enunciador ao expor sobre o direito de posse das terras em discussão.

Há um "clima" de tensão criado ao longo das publicações, verificado na seleção de recursos como os temas e as figuras, o "jogo" entre os termos "invasão" e "ocupação" e entre as "vozes" trazidas para o texto. A utilização de verbos que introduzem o discurso do outro, verbos dicendi(dizer, falar, afirmar), compõem construções que direcionam aos envolvidos - indígenas e não indígenas - o comprometimento pelos fatos narrados.

Inicialmente, em 2016, contamos com três textos publicados pelo Diário MS. No primeiro temos:

Figura 1 - Diário MS, 24/02/2016

Índios dizem que terreno invadido em Dourados pertencia a antepassados

(1) 24 de fevererio de 2016 as $13: 27$

OCUPAÇÃo | De acordo com os indios a região era terra de ocupação tradicional e prometem que vão lutar pela propriedade

${ }^{5}$ Os textos selecionados integram os gêneros notícia e reportagem, mas não fizemos distinção entre eles, pois interessava para esta pesquisa apenas analisar o conteúdo dos textos com o caráter informativo desses gêneros. 


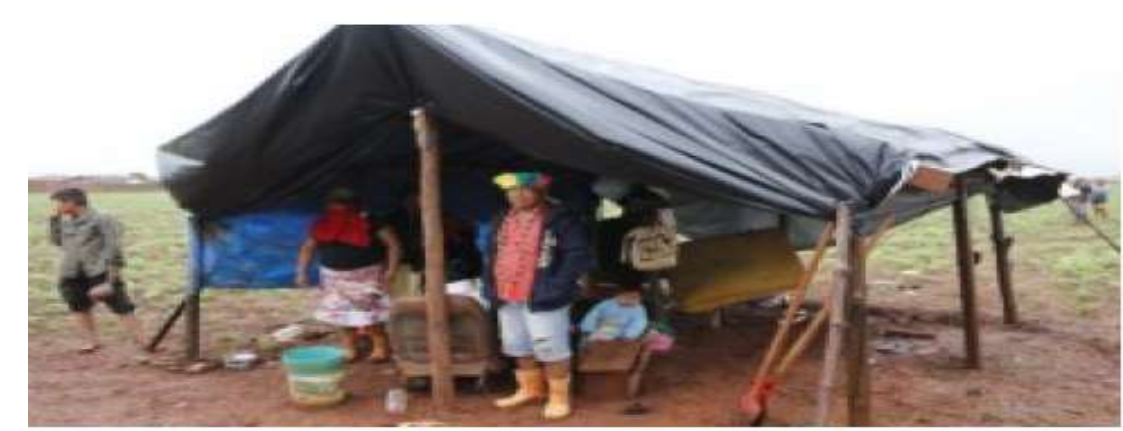

Diário MS

ÍNDIOS esperam a chegada de mais pessoas fortalecer luta pela terra em área ocupada em

Fonte: Índios dizem....(2016).

\section{Dourados}

Nessa publicação, o destaque é para a versão dada pelos indígenas diante da situação, em discurso indireto. Diante desse posicionamento discursivo, verificamos que a debreagem enunciva, normalmente utilizada para produzir 0 efeito de sentido de objetividade no enunciado, provoca o efeito de sentido de subjetividade, já que é o enunciador "traduzindo" as informações para o leitor, a partir da sua visão sobre a situação retratada.

No título "Índios dizem que terreno invadido em Dourados pertencia a antepassados", o uso da palavra "invadido" parece destoar das escolhas encontradas no chapéu "ocupação", no fio, "De acordo com os índios região era terra de ocupação tradicional e prometem que vão lutar pela propriedade", e na legenda da fotografia, "[...] luta pela terra em área ocupada em Dourados". Legenda que ancora a imagem com a representação tradicional da família (homem, mulher e crianças), na condição de espera, desfavorecidos sob o barraco de lona. É como se o título indiciasse a visão do enunciador sobre a situação.

No segundo texto, o verbo "invadir" prevalece, aparecendo no título, na legenda e na referência aos indígenas como "invasores", como consta no fio, reforçando o posicionamento do enunciador em relação à ação divulgada. Vejamos: 
Figura 2 - Diário MS, 08/03/2016

Índios invadem propriedades rurais próximas ao anel viário de Dourados

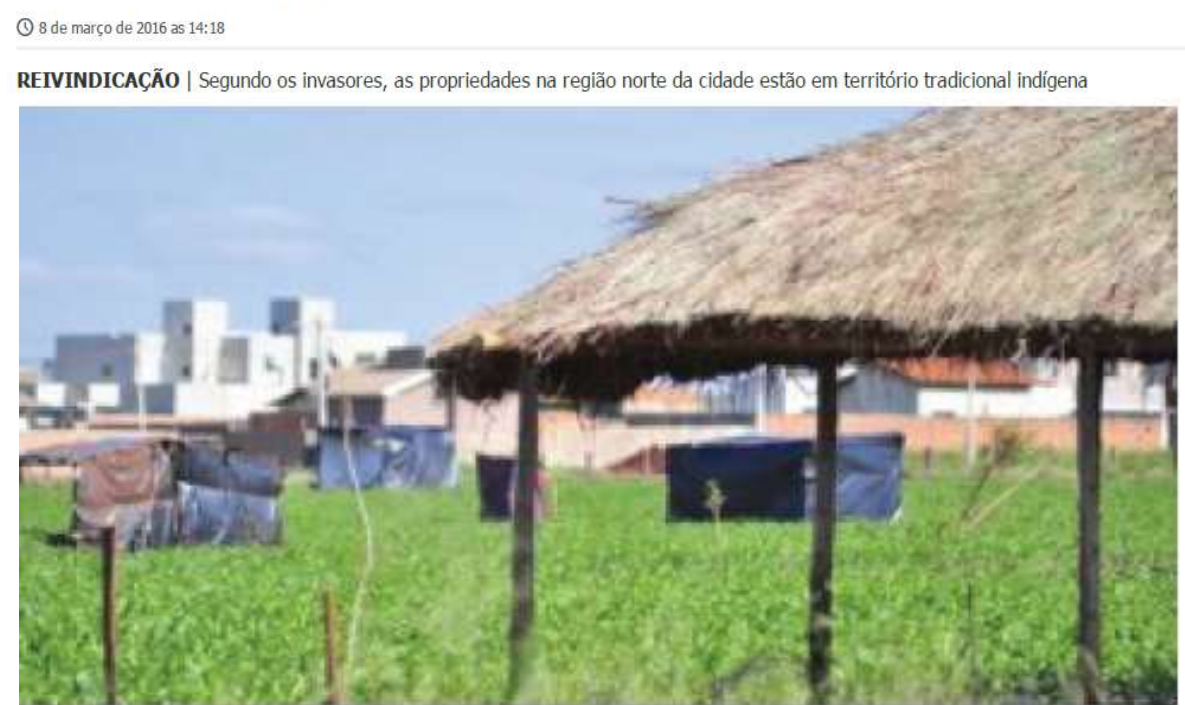

\section{Diário MS}

\section{ÍNDIOS invadiram mais propriedades na região norte de Dourados e reivindicam a posse da terra}

Fonte: Índios invadem... (2016).

Compondo o conjunto, o termo que serve como chapéu, "reinvindicação", indica a natureza da matéria: a reinvindicação dos indígenas em relação às propriedades de Dourados. Na imagem temos a presença de barracos - de sapé no primeiro plano e de lona, no segundo plano -, utilizados pelos indígenas para se estabelecerem na região. Cromaticamente destacam-se em pontos na cor preta e marrom, em meio às plantações, na cor verde, já existentes na área, sobre as quais foram erguidos. Um pouco mais ao fundo, em um terceiro plano da imagem, construções em alvenaria indicam o começo da zona urbana, consequentemente, a expansão das terras indígenas para a cidade. Essa proximidade está dividida por um muro, figura que representa o tema da separação entre os dois mundos, o que é reforçado pela legenda que caracteriza a ação como uma "invasão" ao afirmar que "ÍNDIOS invadiram mais propriedades". Retomando Barthes (1984), verificamos que a legenda ancora o que aparece na imagem, reduz sua polissemia direcionando a leitura do texto para uma visão contrária às decisões indígenas. 
No terceiro texto, o Diário MS publica: "Funai diz que estudo sobre sítios invadidos por índios ocorre há 46 anos". Chama nossa atenção o uso do termo "invadidos" para referir-se à FUNAI (Fundação Nacional do Índio), voz de autoridade que representa os indígenas. Parece ocorrer uma sobreposição de vozes do enunciador "traduzindo" o ponto de vista sobre o caso a partir do seu posicionamento, da sua avaliação. Vejamos: 
Figura 3 - Diário MS, 10/03/2016

Funai diz que estudo sobre sítios invadidos por índios ocorre há 46 anos

(1) 10 de março de 2016 as 13:39

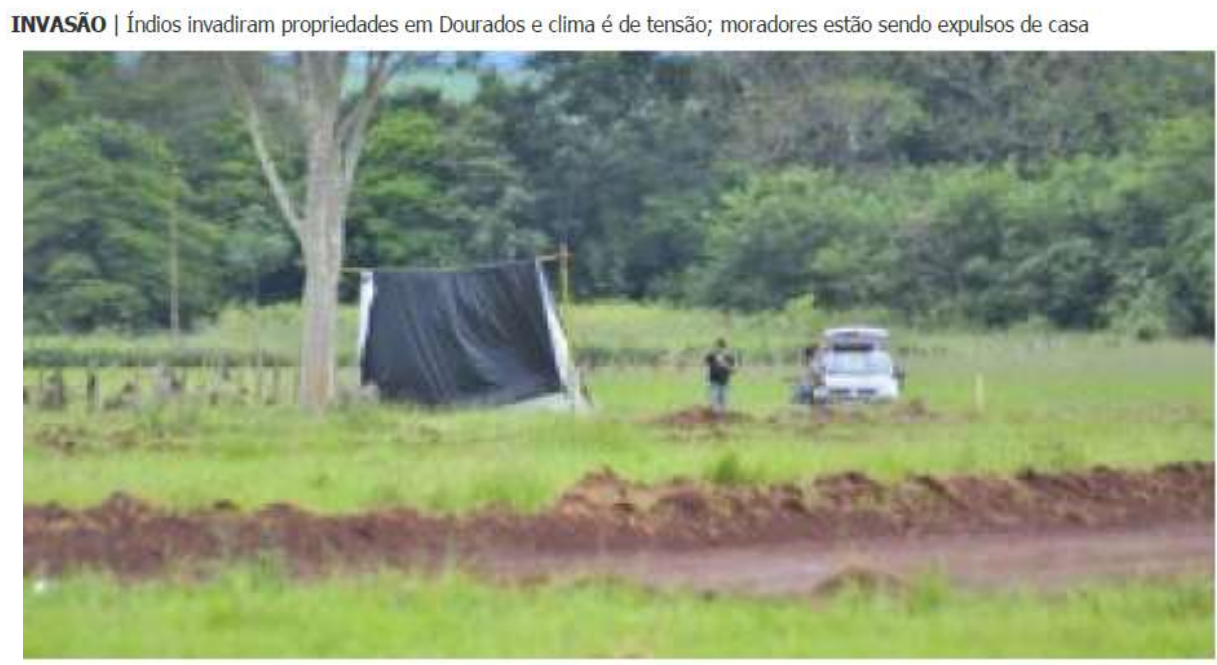

Diário MS

ÍNDIOS montam barraco em sítio invadido em Dourados e proprietários dizem que clima é de tensão

Fonte: Funai... (2016).

O clima de tensão é intensificado no chapéu, nas informações do fio e da legenda, que retomam essa ideia, compondo a isotopia da "invasão" das terras, o que é afirmado segundo a Funai, no título, e ratificado pelos proprietários, não indígenas, na legenda: "dizem que clima é de tensão".

$\mathrm{Na}$ fotografia temos, novamente, destaque para a imagem do barraco de lona utilizado pelos indígenas para estabelecerem-se no local, até que seja resolvida a questão da posse da terra. Há certo distanciamento tomado pelo enunciador fotógrafo: ele opta por manter afastamento do ambiente e dar zoom na câmera para mostrar a situação do local onde estariam os indígenas. Distanciamento que reforça o clima de tensão.

Diante da recorrência aos termos "invasão" e "ocupação", faz-se necessário apresentar uma reflexão sobre essas palavras, pois verifica-se que o uso de "invasão" incita um caráter ilegal nas ações, enquanto "ocupação" 
aparenta mitigar possível ilegalidade. Em uma busca no dicionário on-line Aulete, encontramos as seguintes definições:

Invadir: "(in.va.dir) v.

1. Entrar pela força num lugar e ocupá-lo: $O$ exército invadiu $o$ país vizinho $[. .] .$.

2. Infestar, tomar: Os gafanhotos invadiram as colheitas

3. Fig. Ultrapassar o limite de (de algo delimitado): Invadir direitos alheios

4. Fig. Alastrar-se dominando: O rap invadiu o país; Depois do almoço, invadiu-me o sono

[F.: Do v.lat. invadere.] (INVADIR..., 2017).

Ocupar: "(o.cu.par) v.

1. Preencher, tomar (espaço, lugar) [td. : $A$ enciclopédia ocupa toda a prateleira superior.]

2. Desempenhar (cargo, função, posição) [td. : Foi a primeira mulher a ocupar a presidência do Chile.]

3. Habitar, usar (espaço, lugar) [td. : Ocupou o apartamento durante anos: Só ocupavam a casa nos feriados e domingos.]

4. Utilizar (espaço, aparelho) de forma exclusiva, impedindo-lhe o uso pelos outros [td. : Ocupou o telefone durante horas.]

5. Tomar, capturar militarmente [td. : Os invasores ocuparam Bagdá.]

6. Despertar a atenção de [td. : A briga do casal ocupou a atenção da vizinhança.]

7. Gastar, levar certo período de tempo [td. : As aulas ocupavam todo o seu dia.]

8. Dedicar-se a, cuidar de [tr. + de : Ocupava -se das compras e o irmão cozinhava.] [tdr. + com : Ocupavam as horas livres com a paquera.]

9. Empregar, utilizar [td. : A preparação das fantasias ocupava dez costureiras.]

10. Dedicar-se com afeto; demonstrar cuidados com [tdi. + de : Ocupava -se do doente dia e noite.]

11. Ter por objetivo [tr. + de : Ocupara -se em transmitir as notícias.]

[F.: Do lat. occupare.] (OCUPAR..., 2017).

Na definição para os termos, verificamos que "invasão" remete a uma condição mais reprovável em comparação à "ocupação", como consta na terceira 
classificação: "Ultrapassar o limite de (de algo delimitado): Invadir direitos alheios". Dessa forma, inserido nos discursos analisados, caracteriza a ação dos indígenas como negativa, ao contrário do termo ocupação, que ameniza a condição dos fatos. Notamos que, geralmente, "invadir" está diretamente ligado à versão do não indígena, e "ocupar", à do indígena.

Dando sequência ao acompanhamento das publicações, no dia $14 / 03 / 2016$, os três veículos jornalísticos escrevem sobre o assunto foco das análises neste trabalho. No Diário MS temos:

Figura 4 - Diário MS, 14/03/2016 Invasões de fazendas aumentam em Dourados e índio é ferido em confronto (1) 14 de março de 2016 as $13: 16$

CONFUTO | No sábado, índios invadiram a Fazenda Cristal, ao lado da reserva de Dourados, e mais sítios foram ocupados

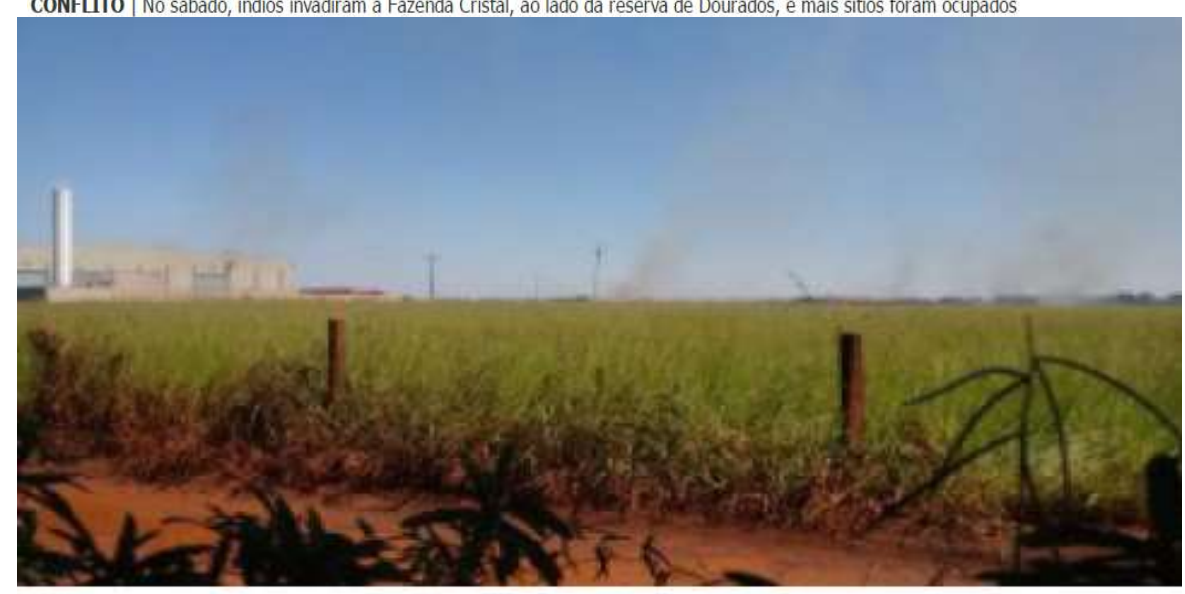

Divulgação ÍNDIOS ampliaram invasões nos arredores da reserva e já ocupam fazenda entre Dourados e Itaporã

Fonte: Invasões...(2016).

Verificamos que o olhar para o conflito é intensificado, como ratifica o chapéu "conflito". No título as "invasões" são ressaltadas juntamente com o detalhe da informação "índio é ferido em confronto". No fio e na legenda esse termo mistura-se a "ocupação", esta que representa a instalação dos indígenas nos locais em questão. Na fotografia temos a imagem que lembra a publicada 
pelo Diário $M S$, no dia 08/03. Apesar de não haver barracos no local, visualizamos, em primeiro plano, a terra e as plantações e, em segundo plano, construções de alvenaria da cidade de Dourados, sugerindo a aproximação da área indígena com o perímetro urbano. O contexto é visto como negativo, conforme assevera a legenda: "ÍNDIOS ampliaram invasões nos arredores da reserva e já ocupam fazenda entre Dourados e Itaporã" (itálico nosso). Novamente, notamos a ênfase no distanciamento do enunciador/fotógrafo por ser este um local de "conflito".

No mesmo dia o Dourados News divulga a sua única publicação sobre a temática:

Figura 5 - Dourados News, 14/03/2016

Região norte já tem sete pontos de invasão e PM teme conflitos

Gizele Almeida

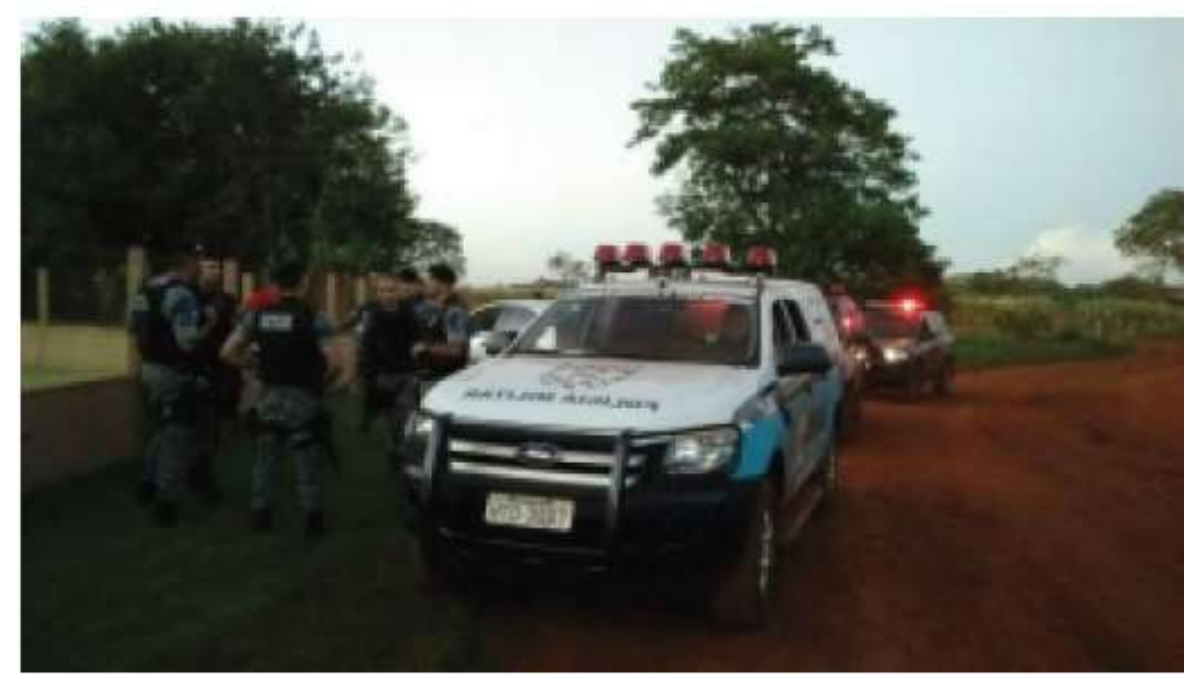

PM foi até o local para manter a ordem; clima era tenso no final da tarde - Foto: Osvaldo Duarte

Fonte: Almeida (2016).

Verifica-se que o "tom" do título é mais enfático, no sentido de indicar o clima de conflito, principalmente pela escolha das palavras "invasão" e "teme". Não menos incisiva é a imagem, apresenta um grupo de policiais e viaturas que 
esteve no local, como esclarece a legenda: "PM foi até o local para manter a ordem; clima era tenso no final da tarde". Os policiais e as viaturas, intervenção policial, representam figuras que remetem à temática "ordem", a qual coloca em relação as oposições de base "ordem versus desordem", "opressão versus liberdade", implicadas nas notícias.

Já o veículo de notícias $O$ Progresso publica:

Figura 6 - O Progresso, 14/03/2016

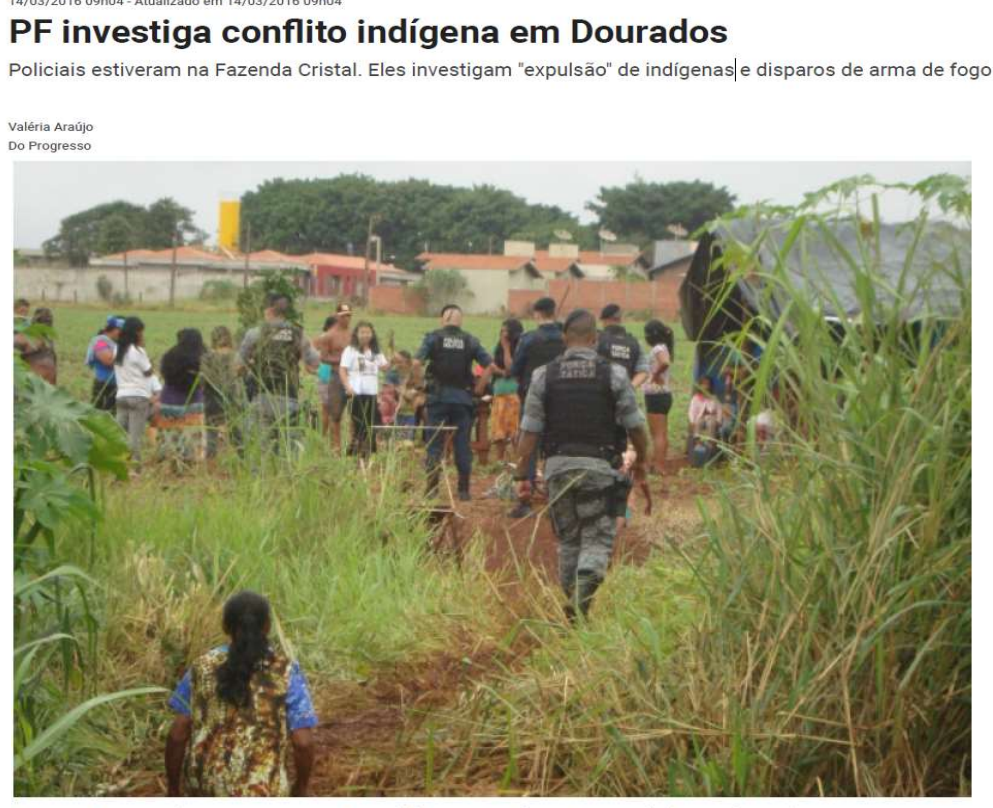

Fonte: Araújo (2016).

Ratificando as colocações dos veículos anteriores, este destaca o conflito entre indígenas e não indígenas, como é reforçado na escolha lexical de "conflito", no título; "expulsão" (palavra que aparece entre aspas, chamando a atenção do enunciatário para avaliar a versão dos fatos), no fio; no detalhe para a seleção da figura "arma de fogo", também no fio, e na construção da imagem. Nessa, temos os policiais da força tática abordando indígenas na primeira ocupação na área urbana em questão, como informa a legenda "Primeira ocupação de terra ocorreu em uma área de loteamento no bairro Monte Carlo".

Ainda sobre a imagem, notamos que o enunciador também se posiciona a certa distância do local. Pelo foco da câmera, ele está numa posição anterior à 
primeira pessoa que aparece na parte inferior da fotografia, a mulher. Em segundo plano, parte meio-superior da imagem, estão os policiais, de costas para o enunciador, eles se misturam ao grupo de indígenas que ocupa o local, ou seja, a sensação é de distanciamento diante da tensão do caso. Além disso, topologicamente, destaca-se o enquadramento dado aos policiais: eles parecem maiores do que os outros sujeitos, organizam-se em paralelo, um ao lado do outro, e eretos, numa condição de superioridade. Dessa forma, constrói-se a condição de submissão dos indígenas, projetando o efeito de opressão.

No dia seguinte, o mesmo jornal publica um texto que coloca em dúvida as ações do grupo de indígenas que lutavam pela posse de terras em Dourados. Vejamos:

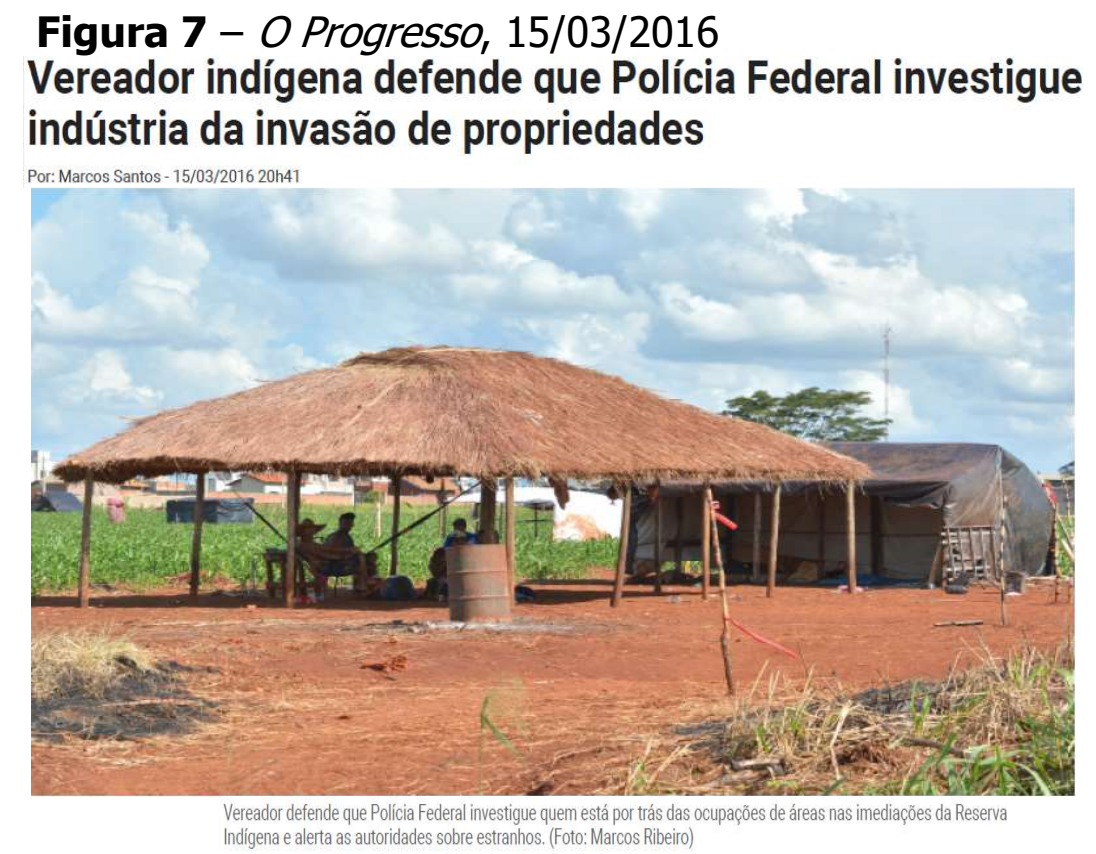

Fonte: Santos (2016).

A acusação apresentada no texto insere uma novidade no acompanhamento dos fatos: a "indústria da invasão de propriedades", o que poderia significar o equívoco das ações do grupo de indígenas favorecendo a manutenção da posse das terras para os não indígenas. O enunciador respaldase apresentando a voz do vereador indígena, tendo em vista a importância da 
participação desse sujeito ao representar politicamente, dentro e fora da aldeia, a defesa do povo indígena. A composição da fotografia não difere muito de outras já analisadas anteriormente, marca a presença dos indígenas nas terras em questão, próximos ao perímetro urbano de Dourados; o estado é de espera.

Ainda entre os meses de março e maio, mais especificamente nos dias 17 e 18 de março; 12, 13 e 20 de abril e 04 de maio, os textos publicados pelo jornal Diário MS apresentaram informações sobre o andamento do pedido de reintegração de posse por parte dos produtores rurais, apoio de entidades, como a associação comercial de Dourados, aos produtores rurais, e resistência dos indígenas. Em suma, essas publicações apresentam uma série de ações envolvendo notificação, mandado e liminar. Justificamos que não nos debruçamos nas análises desses textos, tendo em vista a extensão deste artigo e por julgarmos não serem muito relevantes, pois, como já observado, alguns referem-se essencialmente às informações sobre o andamento jurídico do caso.

No mês de junho, o Diário MS retoma o andamento da situação e publica o seguinte texto:

Figura 8 - Diário MS, 29/06/2016

Ocupados por índios há 4 meses, sítios se transformam em "cidade de lona"

(1) 29 de junhode 2016 as 13:00

TENSÄ0 | Índios tentaram expulsar proprietária de residência ontem e moradores reclamam de lentidão da Justiça

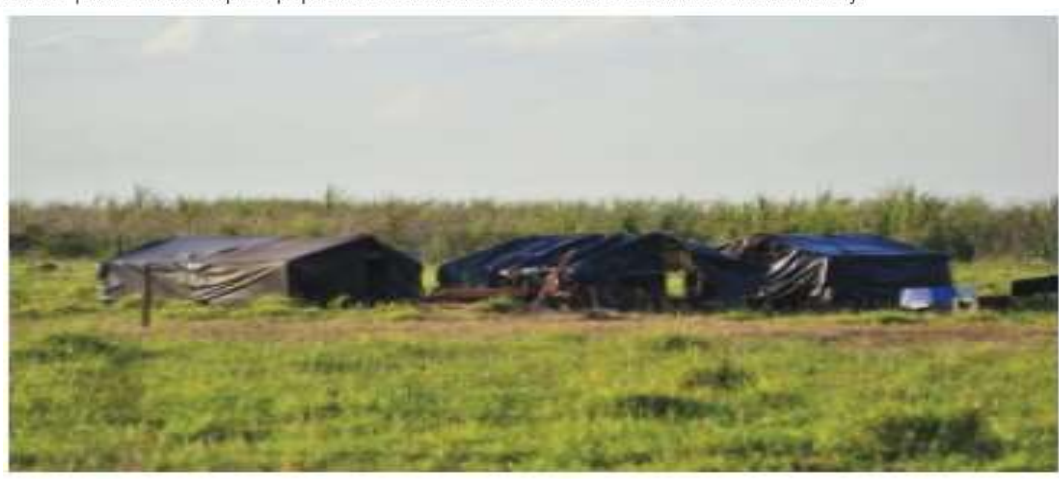

BARRACOS montados por índios em sítios

Arquivo

localizados na região norte de Dourados; invasão

faz quatro meses

Fonte: Ocupados...(2016). 
Nessa publicação, o enunciado verbal parece ligar-se à ideia da ocupação e retoma a questão que vinha sendo noticiada ao longo de determinado período, como indica o título: "ocupados por índios há 4 meses", informação reforçada pela legenda que volta a caracterizar a ação como "invasão": "[...] invasão faz quatro meses". No entanto, chama nossa atenção, no título, a utilização da metáfora "cidade de Iona". Ela enfatiza a quantidade de barracas montadas/afixadas nos sítios em disputa (figura que passa a representar a presença indígena nos locais em foco) e insere o tom de crítica em relação à precariedade das instalações. Além disso, na escolha das informações, o enunciador reporta-se a um caso de "expulsão" de uma proprietária e da "lentidão da Justiça", como aparece no fio: "Índios tentaram expulsar proprietária de residência ontem e moradores reclamam de lentidão da Justiça".

A imagem que ilustra a notícia, buscada em arquivo, ilustra a precariedade, o destaque é para o conjunto de "BARRACOS", como aparece denominado em caixa alta na legenda, centralizados em meio ao verde da paisagem. Permanece o registro da cena a partir de determinada distância. A legenda ratifica o tom ilustrativo da situação, revelando que pouco mudou: "BARRACOS montados por índios" e "invasão faz quatro meses". Verificamos, novamente, que a intenção é demonstrar que o clima de "TENSÃO" perdura, como consta no chapéu.

No mês de julho, 18/07/2016, o Diário MS publica apenas um texto informando sobre a concessão de reintegração dos sítios aos produtores. No mês de outubro parece haver um encaminhamento para a "resolução" do caso, expresso em dois textos, em dias consecutivos, que chamam atenção principalmente pelas imagens, como seguem:

Figura 9 - Diário MS, 25/10/2016

TRF nega recurso e mantém despejo de índios em Dourados

(Q) 25 de atubrode 2016 as $08: 34$ 


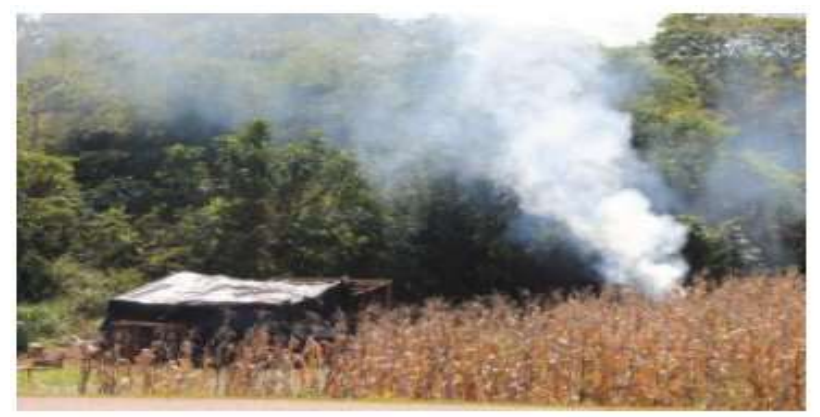

Arquivo

Sítio ocupado por índios no perímetro urbano de Dourados; Funai perdeu recurso e TRF mantém despejo

Fonte: TRF nega...(2016).

Figura 10 - Diário MS, 26/10/2016

Seis meses após invasōes, indios são despejados e barracos desmontados

Q 260 a a a bitrode 20163008:46

Do Campo Grande News

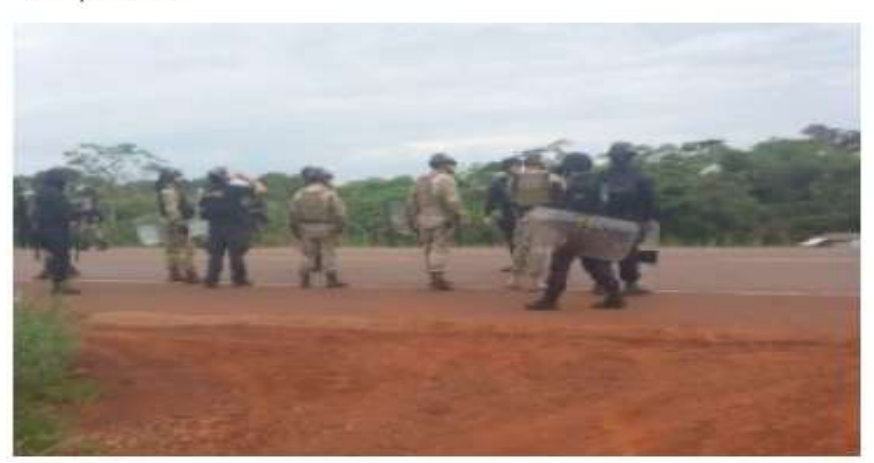

Campo Grande News

Policiais federais e militares durante despejo de índios de dois sítios na região norte de Dourados, ontem de manhã

Fonte: Seis... (2016).

Verificamos que o foco desses textos está na ação de despejo dos indígenas. Mais uma vez parece sobressair a ideia de invasão, como frisado no texto do dia 26 de outubro: "Seis meses após invasões, índios são despejados e barracos desmontados".

Voltando nosso olhar para as imagens, temos, à esquerda, um barraco, como outros que apareceram nas reportagens analisadas anteriormente. Esse representa o local onde estavam acampados os indígenas, enquanto esperavam pela resolução do caso, aqui localizado no limite entre a plantação de milho e a 
mata. O barraco divide esse limite com um foco de fumaça, cena que figurativiza a decisão pelo despejo, como esclarece a legenda "[...] Funai perdeu recurso e TRF mantém despejo". Isso fica reforçado pela segunda imagem, à direita, na qual temos sobre a estrada asfaltada, no limite, "policiais federais e militares durante despejo de índios de dois sítios na região norte de Dourados [...]". Em conjunto, as duas publicações revelam que a ação não é pacífica; há destaque para a força policial, esta que detém o dever e o poder-fazer e está na iminência de realizar a ação e manter a "ordem". Cabe destacar, ainda, que a segunda publicação tem a assinatura de outro portal de notícias, o Campo Grande News, portal de notícias da capital do Estado, ou seja, é um texto reutilizado pelo Diário $M S$, o que não deixa de indicar a repercussão dos fatos.

As publicações anteriores colocam o leitor na expectativa pela solução. Chegamos, então, às duas últimas publicações selecionadas no período investigado, uma de 22 de dezembro de 2016 e a outra de 17 de janeiro de 2017. Nessas, o leitor é informado que a ação de despejo ainda não foi realizada, como mostram os seguintes títulos: "Juiz autoriza despejo em sítios invadidos por índios em março" e "Índios ampliam invasões em lotes urbanos em Dourados". Ou seja, a história continua, o impasse/a situação conflituosa não é resolvida. Vejamos:

Figura 11 - Diário MS, 22/12/2016

Juiz autoriza despejo em sítios invadidos por índios em março

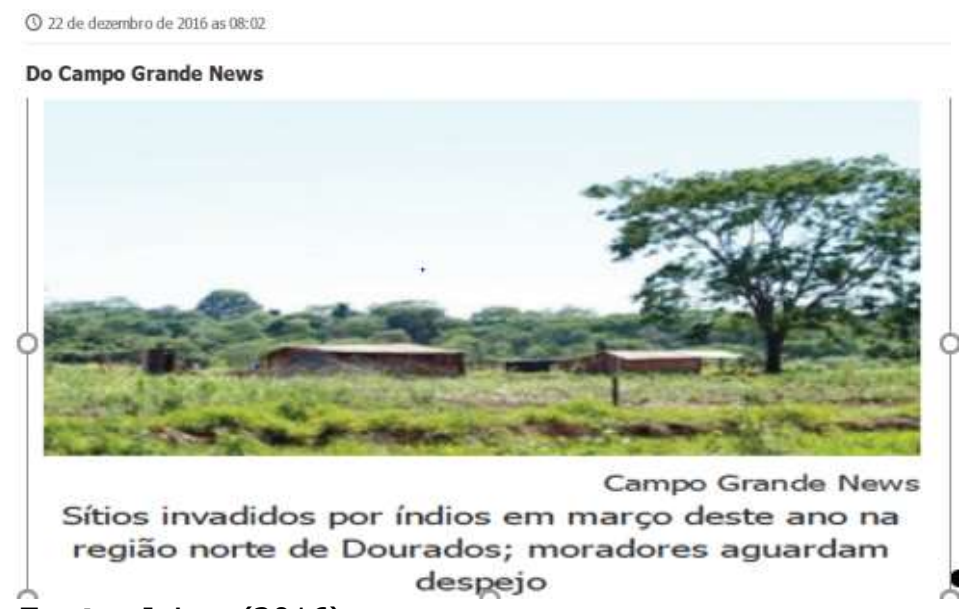

Fonte: Juiz... (2016). 
Figura 12 - Diário MS, 17/01/2017

Índios ampliam invasooesem lotes urbanos em Dourados

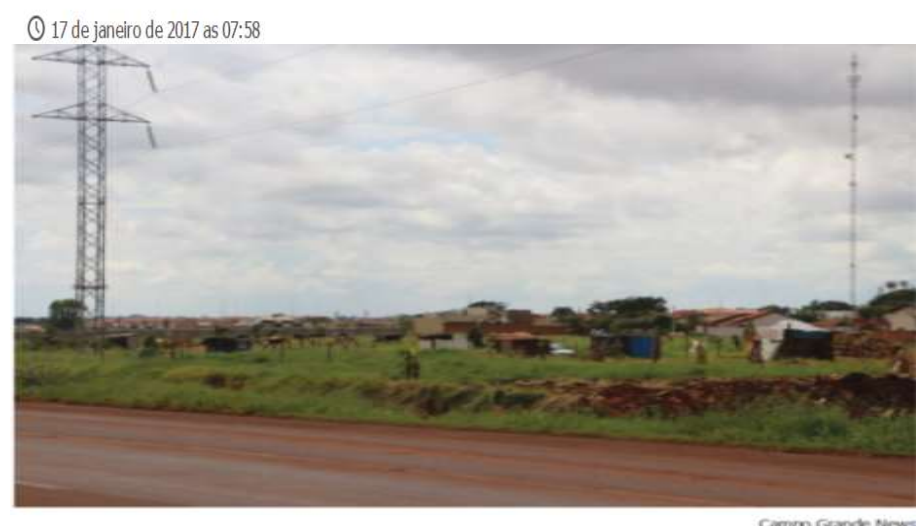

Fonte: Índios ampliam... (2017).

As duas publicações, novamente, carregam as assinaturas do Campo Grande News e reforçam a avaliação da ação dos indígenas como um ato de "invasão", como aparece nos títulos e na primeira legenda. Nas imagens, notamos que há mudança na disposição e representação das casas. Na primeira fotografia, elas não são mais apenas de lona, e, na segunda, as moradias estão ainda mais próximas da zona urbana de Dourados, como explica a legenda "Barracos montados nos fundos do residencial Monte Carlo, ao lado da reserva". Isso evidencia o desenvolvimento das ações dos indígenas ao longo do tempo, afinal as notícias iniciaram em fevereiro de 2016 , isto é, quase um ano. Não menos importante, sublinhamos que as fotografias continuam sendo realizadas a certa distância do local fotografado, marcando o deslocamento, a situação de tensão, o limite. Na segunda imagem, esse limite é figurativizado pela estrada de asfalto que separa a reserva indígena de Dourados e a zona urbana. Nesse caso, os indígenas estão na zona urbana e o enunciador está no limite, observando a situação, na expectativa pela resolução.

\section{Considerações Finais}

Neste artigo, optamos por focalizar nossas análises em textos sobre a expansão das terras indígenas em direção ao perímetro urbano de Dourados, 
uma narrativa não concluída até o final de nossas investigações - o confronto entre o índio e o não índio sobre a "posse de terra" -, mas que revelou muito sobre a relação entre indígenas e não indígenas na região.

As análises de elementos "direcionadores da leitura" dos textos jornalísticos (título, fio, chapéu, fotografia, legenda) mostraram que os enunciadores dos portais de notícias utilizam recursos discursivos para marcar o clima de tensão/conflito em que vivem os sujeitos envolvidos na discussão sobre a posse de terras, temática que acompanha o município desde a sua origem. Destacamos, entre outras escolhas, as figuras utilizadas para representar o tema geral "conflito": "arma de fogo", "os policiais", as "viaturas policiais", elementos do mundo que caracterizam um recorte da realidade para o leitor, a partir do direcionamento pretendido pelo enunciador do texto. Outra temática sublinhada foi a do "limite" entre indígenas e não indígenas, reserva e área urbana, representado nas figuras do "muro", da "estrada", "casas de alvenaria" versus "barracos de lona/ coberturas de sapé". Esse conjunto de temas e figuras compõe um todo de sentido, conforme Barros (2005, p. 66) evidencia "a coerência semântica", cria o efeito de sentido de realidade.

Na construção desse sentido voltado para o clima de tensão, as fotografias desempenham papel importante, ancoradas pelas legendas que auxiliam nos indícios sobre a "tradução" da cena recortada, revelam o posicionamento do enunciador/fotógrafo, quase sempre num deslocamento considerável do local registrado, da cena enfocada. Há distanciamento, "precaução" frente à "zona de confronto" instaurada no questionamento sobre as posses das terras. Ainda que não tenhamos aprofundado a análise plástica das imagens, notamos que 0 recorte é sempre para uma cena; ela representa a situação naquele momento, 0 retrato para que o leitor avalie a situação. Cromaticamente, os barracos nos quais estão os indígenas destacam-se nas cores preta e marrom, normalmente em oposição ao verde das plantações. Topologicamente, chamamos a atenção para os policiais, na condição de superioridade em relação aos indígenas, no texto do 
O Progresso de 14/03/2016. Eideticamente, não notamos contrastes significativos.

A seleção lexical também se revelou importante nessa construção, por isso, destacamos a utilização dos termos "ocupação" e "invasão" como formas de direcionar a leitura das "versões" para a situação, juntamente com as vozes dos envolvidos - indígenas e não indígenas - que são trazidas para as construções, via debreagem enunciva. A utilização de "invasão", normalmente, intensifica o tom de enfrentamento, de possível ilegalidade da ação dos indígenas frente à expansão territorial.

Por fim, esperamos contribuir ao apontar alguns elementos que ajudam a compor os textos jornalísticos e que direcionam a leitura, sobretudo quando tratam de temas como a posse de terras em Dourados. Os textos da mídia exigem a leitura atenta para perceber as estratégias persuasivas usadas pelo enunciador do texto no direcionamento de determinadas interpretações dos fatos.

\section{Referências}

ALMEIDA, Gizele. Região norte já tem sete pontos de invasão e PM teme conflitos. Dourados News, Dourados, MS, 14 mar. 2016. Dourados. Disponível em: www.douradosnews.com.br/. Acesso em: 10 jan. 2017.

ARAÚJO, Valéria. PF investiga conflito indígena em Dourados. O Progresso, Dourados, MS, 14 mar. 2016. Polícia. Disponível em: http://www.progresso.com.br/. Acesso em: 10 jan. 2017.

BARROS, Diana Luz Pessoa de. Teoria semiótica do texto. 4. ed. São Paulo: Ática, 2005.

BARTHES, Roland. O óbvio e o obtuso. Lisboa: Edições 70, 1984.

DECHARAUAU, Patrick. Discurso das mídias. Tradução de Ângela S. M. Corrêa. São Paulo: Contexto, 2006.

DISCINI, Norma. A comunicação nos textos. São Paulo: Contexto, 2005. 
FIORIN, José Luiz. A noção de texto na semiótica. Organon: Revista Científica do Instituto de Letras da Universidade Federal do Rio Grande do Sul, Porto Alegre, RS, v. 9, n. 23, p. 165-176, 1995.

FIORIN, José Luiz. Elementos de análise do discurso. 15. ed. São Paulo: Contexto, 2005.

FUNAI diz que estudo sobre sítios invadidos por índios ocorre há 46 anos. Diário MS, Dourados, MS, 10 mar. 2016. Invasão. Disponível em: http://diarioms.com.br/. Acesso em: 10 jan. 2017.

GREIMAS, Algirdas Julien; COURTÉS, Joseph. Dicionário de semiótica. Tradução de Alceu Dias Lima. São Paulo: Cultrix, 1979.

GUIMARÃES, Elisa. $A$ articulação do texto. 4. ed. São Paulo: Ática, 1995.

HERNANDES, Nilton. Semiótica dos jornais. análise do Jornal Nacional, Folha de São Paulo, Jornal da CBNM, Portal UOL, revista Veja. 2005. $324 \mathrm{f}$. Tese (Doutorado em Linguística) - Universidade de São Paulo, USP, São Paulo, 2005.

ÍNDIOS ampliam invasões em lotes urbanos em Dourados. Diário MS, Dourados, MS, 17 jan. 2017. Campo Grande News. Disponível em: http://diarioms.com.br/. Acesso em: 10 abr. 2017.

ÍNDIOS dizem que terreno invadido em Dourados pertencia a antepassados. Diário MS, Dourados, MS, 24 fev. 2016. Ocupação. Disponível em: http://diarioms.com.br/. Acesso em: 10 jan. 2017.

ÍNDIOS invadem propriedades rurais próximas ao anel viário de Dourados. Diário MS, Dourados, MS, 8 mar. 2016. Reivindicação. Disponível em: http://diarioms.com.br/. Acesso em: 10 jan. 2017.

INVADIR. In: AULETE digital. Disponível em: http://www.aulete.com.br/invadir. Acesso em: 10 jan. 2017.

INVASÕES de fazendas aumentam em Dourados e índio é ferido em confronto. Diário MS, Dourados, MS, 14 mar. 2016. Conflito. Disponível em: http://diarioms.com.br/. Acesso em: 10 jan. 2017.

JUIZ autoriza despejo em sítios, mas índios só devem sair em março. Diário MS, Dourados, MS, 22 dez. 2016. Do Campo Grande News. Disponível em: http://diarioms.com.br/. Acesso em: 10 jan. 2017.

LIMBERTI, Rita de Cássia Pacheco. $A$ imagem do índio: discursos de representações. Dourados: UFGD, 2012. 
MIQUELETTI, Eliane Aparecida. Os casos de desnutrição indígena e a mídia: constituição de imagens e de sentidos. 2007. 139 f. Dissertação (Mestrado em Letras) - Universidade Federal do Mato Grosso do Sul, Três Lagoas, 2007.

MIQUELETTI, Eliane Aparecida. Processos identitários indígenas em Dourados: leitura dos discursos midiáticos e escolares em uma perspectiva semiótica. 2015. 294 f. Tese (Doutorado em Estudos da Linguagem) - Universidade Estadual de Londrina, Londrina, 2015.

OCUPADOS por índios há 4 meses, sítios se transformam em "cidade de lona". Tensão. Diário MS, Dourados, MS, 29 jun. 2016. Disponível em: http://diarioms.com.br/. Acesso em: 10 jan. 2017.

OCUPAR. In: AULETE digital. Disponível em: http://www.aulete.com.br/ocupar. Acesso em: 10 jan. 2017.

ROSSI, Clovis. O que é Jornalismo. São Paulo: Editora Brasiliense, 2005.

SANTOS, Marcos. Vereador indígena defende que Polícia Federal investigue indústria da invasão de propriedades. O Progresso, Dourados, MS, 15 mar. 2016. Disponível em: http://www.progresso.com.br/. Acesso em: 10 jan. 2017.

SEIS meses após invasões, índios são despejados e barracos desmontados. Diário MS, Dourados, MS, 26 out. 2016. Do Campo Grande News. Disponível em: http://diarioms.com.br/. Acesso em: 10 jan. 2017.

TRF nega recurso e mantém despejo de índios em Dourados. Diário MS, Dourados, MS, 25 out. 2016. Disponível em: http://diarioms.com.br/. Acesso em: 10 jan. 2017. 